\title{
Plasma markers of inflammation and incidence of hospitalisations for COPD: results from a population- based cohort study
}

\author{
G Engström, ${ }^{1,2} \mathrm{~N}$ Segelstorm, ${ }^{1} \mathrm{M}$ Ekberg-Aronsson, ${ }^{1} \mathrm{P}$ M Nilsson, ${ }^{1} \mathrm{~F}$ Lindgärde, ${ }^{1}$ \\ C-G Löfdahl'
}

${ }^{1}$ Department of Clinical Sciences, University of Lund, Malmö and Lund, Sweden; ${ }^{2}$ AstraZeneca R\&D, Lund, Sweden

Correspondence to: Professor G Engström, Cardiovascular Epidemiology Research Group, CRC, Malmö University Hospital, S-20502 Malmö, Sweden;

Gunnar.Engstrom@med.lu.se

Received 30 May 2008 Accepted 20 October 2008 Published Online First

6 November 2008

\begin{abstract}
Background: The relationship between plasma markers of inflammation and the incidence of chronic obstructive pulmonary disease (COPD) is still unclear. This populationbased study explored whether raised levels of five inflammation-sensitive plasma proteins (ISPS) predicted hospital admissions for COPD during 25 years of follow-up. Methods: Spirometric tests and measurements of five ISPs (fibrinogen, ceruloplasmin, $\alpha_{1}$-antitrypsin, haptoglobin, orosomucoid) were performed in 5247 apparently healthy men from the city of Malmö (mean age 46 years). The incidence of hospitalisations for COPD was studied in relation to the number of ISPs in the fourth quartile.
\end{abstract}

Results: During the follow-up period, 258 men were admitted to hospital with COPD, 211 of whom were smokers at baseline. The incidence of hospital admissions for COPD was significantly associated with the number of raised ISPs. Adjusted for risk factors, the hazards ratio (95\% Cl) was 1.00 (reference), 1.28 (0.9 to 1.9), 1.29 (0.8 to 2.0) and 2.30 (1.6 to 3.2), respectively, for men with 0, 1, 2 and $\geqslant 3$ ISPs in the top quartile (p for trend $<0.001)$. This relationship was consistent in men with high and low lung function at baseline. The relationship with the incidence of hospital admissions for COPD was largely the same for all individual ISPS.

Conclusion: Raised plasma ISP levels are associated with an increased incidence of COPD requiring hospitalisation.

The relationship between reduced lung function and systemic low-grade inflammation is now widely accepted. ${ }^{1}$ Increased plasma markers of various acute phase proteins have been observed in patients with chronic obstructive pulmonary disease (COPD) and in apparently healthy subjects with reduced forced expiratory volume in $1 \mathrm{~s}$ $\left(\mathrm{FEV}_{1}\right)$ or forced vital capacity (FVC) ${ }^{2-8}$ However, the temporal relationship between systemic lowgrade inflammation and the development of COPD is still unclear. Few have explored whether increased plasma levels of acute phase proteins could predict the development of COPD.

In a study from the CARDIA cohort, fibrinogen was associated with a decline in $\mathrm{FEV}_{1}$ over 5 years of follow-up, ${ }^{9}$ and fibrinogen ${ }^{3}$ and C-reactive protein $(\mathrm{CRP})^{8}$ were found to be associated with the incidence of hospital admissions for COPD in the Copenhagen Heart Study. In two recent studies of CRP in relation to the decline in $\mathrm{FEV}_{1}$, no significant relationships were reported..$^{11} \mathrm{~A}$ recent report from the Cardiovascular Health Study showed that higher levels of fibrinogen, but not CRP, independently predicted greater $\mathrm{FEV}_{1} / \mathrm{FVC}$ decline in elderly individuals. ${ }^{12}$

Previous studies from the Malmö Preventive study have shown that increased plasma levels of fibrinogen, ceruloplasmin, haptoglobin, $\alpha_{1}$-antitrypsin and orosomucoid are associated with an increased incidence of cardiovascular diseases, ${ }^{4}{ }^{13}$ and that the risk of disease increases cumulatively with the number of raised acute phase proteins. Cross-sectional analyses of these markers of inflammation have shown that they are inversely related to lung function. ${ }^{4}$ In the present study we explore whether these proteins are risk factors for the incidence of COPD hospital admissions over a mean follow-up of 25 years.

\section{METHODS}

Between 1974 and 1984, 22444 men participated in a screening programme for the detection of individuals with a high risk for cardiovascular diseases. ${ }^{14}$ Complete birth cohorts from the city of Malmö were invited to take part in the programme and the participation rate was $71 \%$. Determination of five plasma proteins was part of the programme for 6193 men. These men were randomly selected from birth cohorts examined between 1974 and 1982. After exclusion of men with a history of myocardial infarction, stroke or cancer (according to questionnaire), 6075 remained; $\mathrm{FEV}_{1}$ and FVC data were available for 5452 of them. Those with incomplete information about former smoking $(\mathrm{n}=147)$, those who reported that they were controlled for a pulmonary disease in a lung clinic $(\mathrm{n}=40)$ and those with a previous hospital admission for COPD $(\mathrm{n}=18)$ were excluded, leaving 5247 men of mean (SD) age 46.9 (3.6) years (range 28-61) for analysis.

\section{Baseline examinations}

Subjects were categorised into smokers and nonsmokers, and smokers were categorised according to their daily consumption $(\leqslant 9,10-19$ and $\geqslant 20$ cigarettes/day). ${ }^{15}$ Body mass index (BMI) was calculated as weight/height ${ }^{2}\left(\mathrm{~kg} / \mathrm{m}^{2}\right)$. Physical inactivity in spare time was assessed using the question: "Are you mostly engaged in sedentary activities in your spare time, for example, watching $\mathrm{TV}$, reading, going to the movies?"

Respiratory symptoms were assessed by a selfadministered questionnaire. Individuals who reported that they recently or previously had had episodes with chronic productive cough lasting 
Table 1 Baseline characteristics in relation to number of raised inflammation-sensitive protein (ISP) levels

\begin{tabular}{lllll}
\hline & \multicolumn{4}{l}{ Number of raised ISPs } \\
\cline { 2 - 5 } & $\mathbf{0}$ & $\mathbf{1}$ & $\mathbf{2}$ & $\geqslant \mathbf{3}$ \\
& $(\mathbf{n}=\mathbf{2 0 2 3})$ & $\mathbf{( n = 1 4 0 2 )}$ & $\mathbf{( n = 7 9 4 )}$ & $\mathbf{( \mathbf { n } = 1 0 2 8 )}$ \\
\hline Mean (SD) age (years) & $46.6(3.4)$ & $46.9(3.7)$ & $47.0(3.4)$ & $47.3(4.0)$ \\
Mean (SD) height (cm) & $177(7)$ & $176(7)$ & $176(6)$ & $176(7)$ \\
Mean (SD) BMl (kg/m²) & $24.8(3.1)$ & $25.1(3.3)$ & $25.1(3.4)$ & $25.1(3.7)$ \\
Smokers (\%) & 29 & 48 & 61 & 74 \\
$>20$ cigarettes/day (\% of & 19 & 23 & 25 & 31 \\
smokers) & & & & \\
Mean (SD) FEV $(\%$ of predicted) & $98(18)$ & $95(18)$ & $92(17)$ & $89(19)$ \\
Mean (SD) FVC (\% of predicted) & $100(17)$ & $97(16)$ & $95(16)$ & $93(17)$ \\
Chronic bronchitis (\%) & 2.6 & 3.6 & 4.2 & 6.1 \\
Asthma/allergy (\%) & 7.2 & 6.3 & 6.3 & 5.9 \\
\hline
\end{tabular}

Data presented as mean (SD) values or proportions (\%).

$\mathrm{BMI}$, body mass index; $\mathrm{FEV}_{1}$, forced expiratory volume in $1 \mathrm{~s}$; FVC, forced vital capacity.

$>3$ months for $>2$ consecutive years were regarded as having symptoms of chronic bronchitis. ${ }^{16}$

Two questions were used to identify subjects with asthma or allergy: "Have you had asthma symptoms since the age of 20?" and "Do you know or do you suspect that you have asthma, allergic rhinitis, allergic eczema, or allergic swelling of mucous membranes?" A total of 346 men answered positively to at least one of the two questions.

FVC and FEV 1 were measured using a Spirotron apparatus (Drägerwerk AG, Lübeck, Germany) with the subjects in a standing position without noseclips. Specially trained nurses performed the tests. One acceptable manoeuvre with respect to the subject's performance and cooperation was required. The volumes were standardised for age and height using equations derived from linear regressions of 3467 male never smokers in the present cohort. ${ }^{16}$ The following equations were used:

Predicted FEV $1(\mathrm{l})=4.422 \times$ height $(\mathrm{m})-0.038 \times$ age -2.48

Predicted FVC $(\mathrm{l})=6.58 \times$ height $(\mathrm{m})-0.033 \times$ age -5.54

Predicted FEV $1 / \mathrm{FVC}(\%)=1.156-0.1556 \times$ height $(\mathrm{m})-$ $0.002025 \times$ age

Age and height were essentially unrelated to the lung volumes after adjustments. $\mathrm{FEV}_{1}$ and $\mathrm{FVC}$ are expressed as percentages of the predicted values.

\section{Inflammation-sensitive proteins (ISPs)}

Electroimmunoassay was used to assess the plasma levels of acute phase proteins. ${ }^{17}$ The analysis was performed consecutively at the time of study entry. The detection limits were $20 \mathrm{mg} / \mathrm{l}$ for ceruloplasmin, $50 \mathrm{mg} / \mathrm{l}$ for $\alpha_{1}$-antitrypsin and $350 \mathrm{mg} / \mathrm{l}$ for orosomucoid, haptoglobin and fibrinogen. The coefficient of variation was $<5 \% .{ }^{17}$ Median (interquartile range) levels for the ISPs were 3.46 (3.0-4.0) g/l for fibrinogen, $0.80(0.67-0.93) \mathrm{g} / \mathrm{l}$ for orosomucoid, 1.28 (1.09-1.42) g/l for $\alpha_{1}$-antitrypsin, $1.30(0.89-1.75) \mathrm{g} / \mathrm{l}$ for haptoglobin and $0.30(0.26-0.35) \mathrm{g} / \mathrm{l}$ for ceruloplasmin.

The relationships between the ISPs and other risk factors such as smoking ${ }^{43}{ }^{15}$ have been reported previously. We have found that all five ISPs are associated with different cardiovascular diseases and that the hazard ratios (HR) are approximately the same for all ISPs. ${ }^{13} \mathrm{~A}$ composite score (ie, the number of ISPs in the fourth quartile) was therefore constructed from these proteins. Cronbach's alpha for this score is 0.65 in this sample. This score has been associated with cardiovascular diseases in many previous studies. ${ }^{413} 15$

\section{Follow-up}

The Swedish hospital discharge register was used for case retrieval. This register has been operating in the south of Sweden during the entire follow-up period and has covered the whole of Sweden since 1987. All men were followed from the baseline examination until admission to hospital with COPD, death, emigration from Sweden or 31 December 2005, whichever came first. Admissions to hospital with COPD were defined as cases with a discharge diagnosis of COPD (490-492, 496 (ICD-9) or J40-J44 (ICD-10)) as one of the first three listed diagnoses. In addition, hospital admissions with COPD as the primary diagnosis were analysed separately.

\section{Statistical analyses}

Correlations between ISPs and lung function variables were assessed using Pearson correlation coefficients. One-way ANOVA and logistic regression was used to compare the distribution of risk factors in relation to the number of raised ISPs. The Kaplan-Meier test with log-rank statistics and Cox proportional hazards regression was used to study the incidence of COPD hospitalisations in relation to ISPs. The covariates for the Cox model were selected a priori from factors that are

Table 2 Correlations between lung function and plasma proteins

\begin{tabular}{lccccc}
\hline & $\boldsymbol{\alpha}_{1}$-Antitrypsin & Orosomucoid & Ceruloplasmin & Fibrinogen & Haptoglobin \\
\hline All men ( $\mathrm{n}=5247)$ & & & & & \\
FEV 1 (\% predicted) & -0.13 & -0.16 & -0.14 & -0.13 & -0.17 \\
FVC (\% predicted) & -0.12 & -0.13 & -0.12 & -0.13 & -0.15 \\
$\alpha_{1}$-Antitrypsin & 1 & 0.34 & 0.33 & 0.32 & 0.26 \\
Orosomucoid & & 1 & 0.54 & 0.41 & 0.44 \\
Ceruloplasmin & & & 1 & 0.37 & 0.34 \\
Fibrinogen & & & & 1 & 0.43 \\
& & & & & \\
Non-smokers ( $=2749)$ & & -0.13 & -0.09 & -0.10 & -0.10 \\
FEV $1 \%$ predicted) & -0.08 & -0.12 & -0.10 & -0.11 & -0.11 \\
FVC (\% predicted) & -0.10 & 0.27 & 0.27 & 0.26 & 0.18 \\
$\alpha_{1}$-Antitrypsin & 1 & 1 & 0.52 & 0.37 & 0.38 \\
Orosomucoid & & & 1 & 0.33 & 0.28 \\
Ceruloplasmin & & & & 1 & 0.35 \\
Fibrinogen & & & & & \\
\hline
\end{tabular}

All correlations are significant at the 0.01 level (two-tailed).

$\mathrm{FEV}_{1}$, forced expiratory volume in $1 \mathrm{~s}$; FVC, forced vital capacity. 


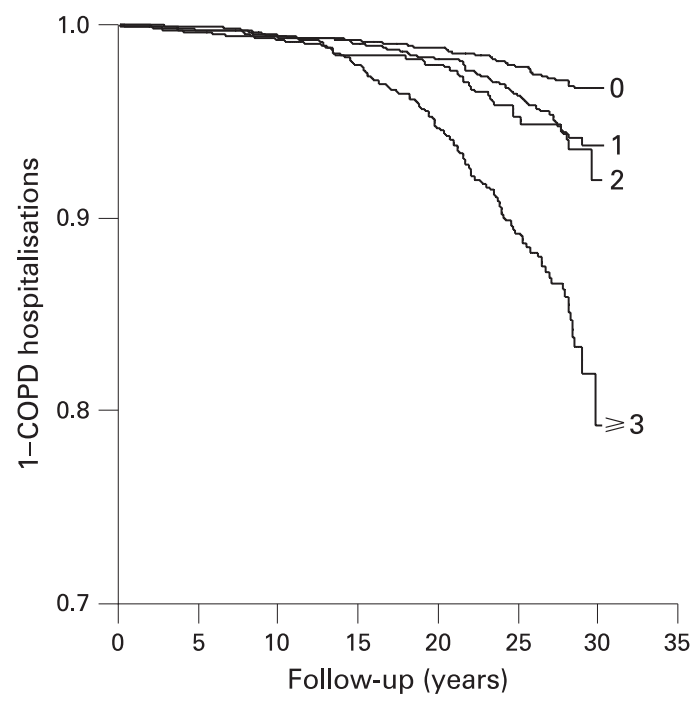

Figure 1 Incidence of hospitalisations for chronic obstructive pulmonary disease (COPD) in men with $0,1,2$ and $\geqslant 3$ raised inflammation-sensitive plasma protein levels in the fourth quartile $(\mathrm{p}<0.001$, log rank test).

known to be associated with low-grade systemic inflammation and the incidence of COPD. Age, BMI, $\mathrm{FEV}_{1}$ (\% of predicted values) were modelled as continuous variables. Current smoking, former smoking, chronic bronchitis and the number of raised ISPs were modelled as categorical variables. The $p$ value for trend was calculated by modelling the number of raised ISPs as an ordinal variable. The fit of the proportional hazards model was confirmed by plotting the incidence of COPD over time for the different risk factors. There was no indication that the proportionality assumption was violated. SPSS software (Version 11.5) was used in all statistical calculations.

\section{RESULTS}

\section{Baseline characteristics}

The baseline characteristics of the cohort in relation to the raised ISP levels are presented in table 1.

Table 2 presents the correlation coefficients between the individual ISPs, FEV 1 and FVC. FEV 1 and FVC were inversely related to the ISPs in all men and in the separate analysis of nonsmokers.

\section{Incidence of COPD hospitalisations}

During the mean follow-up of 25 years, 258 men were admitted to hospital with a discharge diagnosis of COPD and 132 of them had COPD as the primary diagnosis. The incidence of COPD hospitalisations was strongly related to the number of raised
ISPs (fig 1, table 3). The increased incidence in men with $\geqslant 3$ raised ISPs persisted after adjustments for possible confounding factors (table 3). Of the variables in the final Cox regression model, age (HR per 1 year 1.10 (95\% CI 1.06 to 1.14)), BMI (HR per $1 \mathrm{~kg} / \mathrm{m}^{2} 0.95$ (95\% CI 0.91 to 0.98)), chronic bronchitis (HR 2.1 (95\% CI 1.4 to 3.0$)$ ), $\mathrm{FEV}_{1}$ (\% predicted) (HR per $1 \% 0.96$ (95\% CI 0.95 to 0.96)) and current smoking (HR 3.6 (95\% CI 2.2 to 5.8)) were significantly associated with the incidence of COPD hospitalisations.

The analysis was rerun after excluding 346 subjects who reported asthma or allergic symptoms at the baseline examination. A total of 221 incident COPD hospitalisations remained in the analysis. The relationship between the ISPs and the incidence of COPD hospitalisations remained significant and was essentially unchanged.

The results were also essentially unchanged if only cases with $\mathrm{COPD}$ as the primary diagnosis were used in the analysis.

\section{Incidence of COPD hospitalisations in relation to initial lung function}

The sample was divided into three groups according to the baseline $\mathrm{FEV}_{1} / \mathrm{FVC}$ values: low (in the low 5\% of the distribution, $\mathrm{n}=259$ ), low-normal (in the 5-50th percentile, $\mathrm{n}=2364$ ) and high (in the top $50 \%$ of the distribution, $\mathrm{n}=2624)$. Among men with a low $\mathrm{FEV}_{1} / \mathrm{FVC}, 67(11.8 / 1000$ person-years) were admitted to hospital with COPD during the follow-up period. The HRs adjusted for risk factors were 1.00 (reference), 1.2 (95\% CI 0.54 to 2.7 ), 1.2 (95\% CI 0.51 to 2.9 ) and 2.1 ( $95 \%$ CI 1.02 to 4.1 ), respectively, in men with $0,1,2$ and $\geqslant 3$ raised ISPs. Among men with an initially low-normal FEV $1 / F V C$, 130 (2.2/1000 person-years) were admitted to hospital with COPD. The HRs in this group were 1.00 (reference), 1.3 (95\% CI 0.80 to 2.2 ), 1.4 (95\% CI 0.76 to 2.4 ) and 2.0 (95\% CI 1.2 to 3.3), respectively. In men with a high $\mathrm{FEV}_{1} / \mathrm{FVC}, 61(0.9 / 1000$ person-years) were admitted to hospital with COPD. The adjusted HRs were 1.00, 1.3 (95\% CI 0.60 to 2.9), 1.1 (95\% CI 0.42 to 2.8 ) and 3.3 (95\% CI 1.6 to 6.6 ), respectively, in men with $0,1,2$ and $\geqslant 3$ raised ISPs.

\section{Incidence of COPD hospitalisations in relation to smoking}

Of the cases with COPD, 211 were current smokers at the baseline examination, 27 were former smokers and 20 were never smokers (table 4). Of the 27 former smokers, 22 had been smoking for $>10$ years. The age-adjusted $\mathrm{HR}$ of COPD hospitalisations was significantly increased in men with $\geqslant 3$ raised ISPs, even in separate analyses of never smokers and former smokers. It should be noted, however, that these analyses were based on small numbers of cases (table 4).

Table 3 Incidence of COPD hospitalisations during 25 years of follow-up in relation to number of raised inflammation-sensitive plasma proteins (ISPs) in the fourth quartile

\begin{tabular}{|c|c|c|c|c|c|}
\hline & \multicolumn{4}{|c|}{ Number of raised ISPs } & \multirow{2}{*}{$\begin{array}{l}\text { p Value } \\
\text { for trend }\end{array}$} \\
\hline & $0(n=2023)$ & $1(n=1402)$ & $2(n=794)$ & $\geqslant 3(n=1028)$ & \\
\hline $\begin{array}{l}\text { COPD, n (per } 1000 \text { person- } \\
\text { years) }\end{array}$ & $52(1.0)$ & $61(1.7)$ & $37(2.0)$ & $108(4.6)$ & \\
\hline Age-adjusted HR (95\% Cl) & 1.0 & $1.76(1.2$ to 2.5$)$ & $2.03(1.3$ to 3.1$)$ & $5.08(3.6$ to 7.1$)$ & $<0.001$ \\
\hline $\begin{array}{l}\text { Risk factor-adjusted HR } \\
(95 \% \mathrm{Cl})^{*}\end{array}$ & 1.0 & $1.28(0.88$ to 1.9$)$ & $1.29(0.84$ to 2.0$)$ & 2.30 (1.6 to 3.2$)$ & $<0.001$ \\
\hline
\end{tabular}

$\mathrm{Cl}$, confidence interval; COPD, chronic obstructive pulmonary disease; HR, hazard ratio.

${ }^{*}$ Adjusted for age, current and former smoking, body mass index, forced expiratory volume in $1 \mathrm{~s}$ (\% of predicted values) and chronic bronchitis. 
Table 4 COPD hospitalisations during 25 years of follow-up in relation to number of raised inflammationsensitive plasma proteins (ISPs) and smoking status

\begin{tabular}{|c|c|c|c|c|}
\hline & \multicolumn{4}{|c|}{ Number of raised ISPs } \\
\hline & 0 & 1 & 2 & $\geqslant 3$ \\
\hline Never smokers & $\mathrm{n}=742$ & $\mathrm{n}=388$ & $\mathrm{n}=149$ & $\mathrm{n}=136$ \\
\hline COPD, n (per 1000 person-years) & $5(0.3)$ & $10(1.0)$ & $1(0.3)$ & $4(1.2)$ \\
\hline Age-adjusted HR (95\% Cl) & 1.0 & $3.5(1.2$ to 10.4$)$ & $1.0(0.1$ to 8.2$)$ & $4.3(1.1$ to 16.3$)$ \\
\hline Former smokers & $\mathrm{n}=704$ & $\mathrm{n}=337$ & $\mathrm{n}=164$ & $\mathrm{n}=129$ \\
\hline COPD, n (per 1000 person-years) & $12(0.7)$ & $6(0.7)$ & $3(0.7)$ & $6(2.0)$ \\
\hline Age-adjusted HR (95\% Cl) & 1.0 & $1.0(0.39$ to 2.8$)$ & $1.1(0.30$ to 3.8$)$ & $2.9(1.1$ to 7.8$)$ \\
\hline Current smokers & $\mathrm{n}=577$ & $\mathrm{n}=677$ & $\mathrm{n}=481$ & $\mathrm{n}=763$ \\
\hline COPD, n (per 1000 person-years) & $35(2.5)$ & $45(2.8)$ & $33(3.0)$ & $98(5.8)$ \\
\hline Age-adjusted HR $(95 \% \mathrm{Cl})$ & 1.0 & $1.1(0.72$ to 1.8$)$ & $1.2(0.76$ to 2.0$)$ & $2.5(1.7$ to 3.6$)$ \\
\hline
\end{tabular}

$\mathrm{Cl}$, confidence interval; $\mathrm{COPD}$, chronic obstructive pulmonary disease; HR, hazard ratio.

Relationship between individual ISPs and COPD hospitalisations All ISPs were significantly associated with the incidence of COPD after adjustment for age (table 5). The associations between the individual ISPs and COPD hospitalisations remained significant after adjustment for risk factors.

The number of men with $\alpha_{1}$-antitrypsin deficiency was small in this cohort and only nine men had concentrations below $50 \mathrm{mg} / \mathrm{dl}$. The results were unchanged after exclusion of this group.

\section{DISCUSSION}

Several cross-sectional studies have reported inverse relationships between markers of inflammation and lung function. ${ }^{1-8}$ However, few have explored whether a low-grade inflammation in apparently healthy men, as measured by raised acute phase proteins in plasma, could predict future admission to hospital for COPD. This study shows that the incidence of hospital admissions for COPD was strongly related to the number of raised acute phase proteins. The ISPs were measured at a mean age of 46 years and they predicted hospital admission for COPD over a very long time period. This relationship remained significant after adjustments for initial lung function and other potential confounding factors.

Smoking is the most important risk factor for COPD in the general population, and smoking is a major cause of systemic low-grade inflammation. ${ }^{15}$ In this study, 211 out of 258 subjects with COPD were current smokers at the baseline examination. However, relationships between $\geqslant 3$ raised ISPs and the incidence of COPD hospitalisations were also observed in never smokers and former smokers. Because of the small number of cases, we cannot draw any conclusion about the association between ISPs and COPD hospitalisations in never smokers. The results suggest, however, that $\geqslant 3$ raised ISPs may be a marker of increased vulnerability regardless of smoking status.

Table 5 Relationships between individual inflammation-sensitive plasma proteins (ISPs) and hospital admissions for chronic obstructive pulmonary disease (COPD) over 25 years of follow-up

\begin{tabular}{lll}
\hline & Age-adjusted & Risk factor-adjusted* \\
\hline Fibrinogen (per $0.8 \mathrm{~g} / \mathrm{l})$ & $1.46(1.3$ to 1.6$)$ & $1.25(1.1$ to 1.4$)$ \\
Haptoglobin (per $0.68 \mathrm{~g} / \mathrm{l})$ & $1.69(1.5$ to 1.9$)$ & $1.34(1.2$ to 1.5$)$ \\
Ceruloplasmin (per $0.067 \mathrm{~g} / \mathrm{l})$ & $1.55(1.4$ to 1.7$)$ & $1.25(1.1$ to 1.4$)$ \\
$\alpha_{1}$-Antitrypsin (per $\left.0.27 \mathrm{~g} / \mathrm{l}\right)$ & $1.50(1.3$ to 1.7$)$ & $1.16(1.0$ to 1.3$)$ \\
Orosomucoid (per $0.20 \mathrm{~g} / \mathrm{l})$ & $1.49(1.3$ to 1.7$)$ & $1.26(1.1$ to 1.4$)$
\end{tabular}

Expressed as hazards ratios (95\% confidence interval) per 1 standard deviation.

${ }^{*}$ Adjusted for age, current and former smoking, body mass index, forced expiratory volume in $1 \mathrm{~s}$ (\% of predicted values) and chronic bronchitis.
The reason for the association between ISPs and COPD is unclear. The inflammatory proteins were raised many years before the patients were hospitalised with COPD, and high ISP levels were associated with the incidence of COPD hospitalisations even after adjustments for initial lung function. Significant relationships were also observed in men who initially had high $\mathrm{FEV}_{1}$ /FVC, in the top $50 \%$ of the distribution. Reverse confounding (ie, that impaired lung function caused raised ISPs) is therefore an unlikely explanation.

These plasma proteins are widely used as downstream markers of inflammation and their synthesis is regulated by different proinflammatory cytokines. ${ }^{18}{ }^{19}$ It is also widely recognised that COPD is an inflammatory disease. ${ }^{120-23}$ Raised ISPs could thus be a marker of a predisposition to exaggerated inflammatory responses which could cause increased ISPs, reduced lung function and incidence of COPD. This predisposition could be genetically determined. ${ }^{23}{ }^{24}$ The fact that high ISP levels were risk factors even in men who initially had $\mathrm{FEV}_{1} / \mathrm{FVC}$ in the high range supports the view that these proteins are associated with the development of COPD. However, because admission to hospital with COPD was the end point in this study, an alternative explanation could be that these inflammatory markers indicate an increased risk of COPD exacerbations in vulnerable individuals rather than the development of COPD.

The health examination programme was performed several years before the now commonly used guidelines for standardisation of spirometry were published. The equipment and procedure of the lung function test did not meet the standards of these guidelines. For example, only one acceptable test was required and no noseclips were used. Despite this limitation, previous studies from this cohort have shown that the validity of the lung function tests is acceptable. ${ }^{41625}$

The end points in this study were retrieved from the national Swedish hospital discharge register. There is a considerable overlap between COPD and, for example, heart failure, ${ }^{26}$ and one question is whether the diagnoses are valid. However, the results were essentially the same if the study was limited to cases with COPD as the primary diagnosis, and these cases are most likely to be accurate. Furthermore, the diagnosis was confirmed during the stay in hospital. The strong relationships between initial lung function, smoking and COPD hospitalisations also support the view that the diagnoses are valid. It is obvious, though, that many individuals with less severe COPD are treated as outpatients and therefore were not included in this study. This study only explored the relationship with the incidence of COPD requiring admission to hospital, which generally means the most severe cases. 
This population-based study of initially healthy middle-aged men showed that the incidence of hospital admissions with COPD was increased in those with raised levels of acute phase proteins in plasma. These proteins may be markers of increased vulnerability for the development of COPD.

Funding: The study was supported by grants from the Swedish Heart and Lung Foundation, the Swedish Research Council, Malmö University Hospital and grants from LU-ALF.

Competing interests: GE is employed as senior epidemiologist by AstraZeneca R\&D. C-GL has been paid for lectures by AstraZeneca, Boehringer-Ingelheim, GlaxoSmithKline and Pfizer; taken part and been paid for ad hoc advisory boards for the same companies; and has had institutional support as unrestricted grants from AstraZeneca, Boehringer-Ingelheim and GlaxoSmithKline.

Ethics approval: The health service authority of Malmö approved and funded the screening programme. All participants gave informed consent.

\section{REFERENCES}

1. Gan W0, Man SF, Senthilselvan A, et al. Association between chronic obstructive pulmonary disease and systemic inflammation: a systematic review and a metaanalysis. Thorax 2004;59:574-80.

2. Sin DD, Man SF. Why are patients with chronic obstructive pulmonary disease at increased risk of cardiovascular diseases? The potential role of systemic inflammation in chronic obstructive pulmonary disease. Circulation 2003;107:1514-9.

3. Dahl M, Tybjaerg-Hansen A, Vestbo J, et al. Elevated plasma fibrinogen associated with reduced pulmonary function and increased risk of chronic obstructive pulmonary disease. Am J Respir Crit Care Med 2001:164:1008-11.

4. Engström G, Lind P. Hedblad B, et al. Lung function and cardiovascular risk: relationship with inflammation-sensitive plasma proteins. Circulation 2002;106:2555-60.

5. Mannino DM, Ford ES, Redd SC. Obstructive and restrictive lung disease and markers of inflammation: data from the Third National Health and Nutrition Examination. Am J Med 2003;114:758-62.

6. Melbye H, Halvorsen DS, Hartz I, et al. Bronchial airflow limitation, smoking, body mass index, and statin use are strongly associated with the $\mathrm{C}$-reactive protein level in the elderly. The Tromso Study 2001. Respir Med 2007;101:2541-9.

7. Broekhuizen R, Wouters EF, Creutzberg EC, et al. Raised CRP levels mark metabolic and functional impairment in advanced COPD. Thorax 2006;61:17-22.

8. Dahl M, Vestbo J, Lange $\mathrm{P}$, et al. C-reactive protein as a predictor of prognosis in chronic obstructive pulmonary disease. Am J Respir Crit Care Med 2007;175:250-5.
9. Thyagarajan B, Jacobs DR, Apostol GG, et al. Plasma fibrinogen and lung function: the CARDIA Study. Int J Epidemiol 2006;35:1001-8.

10. Fogarty AW, Jones S, Britton JR, et al. Systemic inflammation and decline in lung function in a general population: a prospective study. Thorax 2007;62:515-20.

11. Shaaban R, Kony S, Driss F, et al. Change in C-reactive protein levels and FEV1 decline: a longitudinal population-based study. Respir Med 2006;100:2112-20.

12. Jiang R, Burke GL, Enright PL, et al. Inflammatory markers and longitudinal lung function decline in the elderly. Am J Epidemiol 2008;168:602-10.

13. Engström G, Lind P, Hedblad B, et al. Effects of cholesterol and inflammationsensitive plasma proteins on incidence of myocardial infarction and stroke in men. Circulation 2002;105:2632-7.

14. Berglund G, Eriksson KF, Israelsson B, et al. Cardiovascular risk groups and mortality in an urban swedish male population: the Malmö Preventive Project. J Intern Med 1996;239:489-97.

15. Lind $\mathbf{P}$, Engström G, Stavenow L, et al. Risk of myocardial infarction and stroke in smokers is related to plasma levels of inflammation-sensitive proteins. Arterioscler Thromb Vasc Biol 2004;24:577-82.

16. Ekberg-Aronsson M, Pehrsson K, Nilsson JA, et al. Mortality in GOLD stages of COPD and its dependence on symptoms of chronic bronchitis. Respir Res 2005;6:98.

17. Laurell CB. Electroimmuno assay. Scand J Clin Lab Invest Supp/ 1972;124:21-37

18. Gabay C, Kushner I. Acute-phase proteins and other systemic responses to inflammation. N Engl J Med 1999;340:448-54.

19. Moshage H. Cytokines and the hepatic acute phase response. J Pathol 1997;181:257-66.

20. Fang $\mathbf{0}$, Liu X, Al-Mugotir M, et al. Thrombin and TNF-alpha/L-1beta synergistically induce fibroblast-mediated collagen gel degradation. Am J Respir Cell Mol Biol 2006;35:714-21.

21. Johnson JL, Moore EE, Tamura DY, et al. Interleukin-6 augments neutrophil cytotoxic potential via selective enhancement of elastase release. J Surg Res 1998; 76:91-4.

22. Tetley TD. Inflammatory cells and chronic obstructive pulmonary disease. Curr Drug Targets Inflamm Allergy 2005;4:607-18.

23. Yanbaeva DG, Dentener MA, Creutzberg EC, et al. Systemic inflammation in COPD: is genetic susceptibility a key factor? COPD 2006;3:51-61.

24. Sunyer J, Pistelli R, Plana E, et al. Systemic inflammation, genetic susceptibility and lung function. Eur Respir J 2008;32:92-7.

25. Engström G, Hedblad B, Janzon L. Reduced lung function predicts increased fatality in future cardiac events. A population-based study. J Intern Med 2006:260:560-7.

26. Rutten FH, Cramer MJ, Lammers JW, et al. Heart failure and chronic obstructive pulmonary disease: an ignored combination? Eur J Heart Fail 2006;8:706-11. 